\title{
Agricultural Value Creation through Effective Supply Chain Management
}

\author{
Bowon Kim* \\ Operations Strategy and Management Science, KAIST Business School, Korea
}

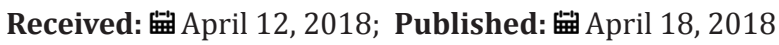

*Corresponding author: Bowon Kim, Operations Strategy and Management Science, KAIST Business School, Korea

\begin{abstract}
Agriculture is the most important industry for humanity. Unfortunately, however, it is also one of the least effectively managed industries. It is true that for the last several decades, there have been enormous scientific advancements that have increased the agricultural productivity. However, the question is whether the world has been able to reap the benefits to the fullest extent of such scientific advancements. The agricultural supply chain is characterized with an extremely long and fragmented system consisting of many gatekeepers throughout the value chain. As a result, it is vulnerable to a serious systemic malfunctioning such as the bullwhip effect. When a supply chain is inflicted by the bullwhip effect, it suffers huge inefficiencies, which include increasing costs, hampering innovation, and weakening problem solving capability. Unless it overcomes such inefficiencies, the industry as a whole will lose its competitiveness and perish eventually. As such, in order for the agricultural industry to sustain and thrive, it is vital to implement supply chain strategy effectively through coordination among the entire participants in the agricultural value chain.
\end{abstract}

\section{Introduction}

There is no doubt about that the agricultural industry is the most essential one for humanity [1]. It also employs a great number of people, providing economic means to them. But it is not easy to answer whether the agricultural industry is an effective one. On the quite contrary, the industry is perhaps the least effectively managed one for the last several thousand years. As people in the world are enjoying longevity, the world consumes more and more food. Can the world's agricultural industry feed all the people on earth? It is a vital question. If the earth capacity is limited and the crops are not produced enough, the only possible solution is to increase the productivity of the agricultural industry. In order to find ways to increase such productivity, we first have to understand why the

productivity of the agricultural industry is so low. Then we can suggest how the agricultural industry changes itself to be more productive and effective. In this paper, we endeavor to answer the question from a value chain perspective.

\section{The Agricultural Value Chain}

Every industry has a value chain. It is usual that the agricultural industry has a long and quite fragmented value chain. For the sake of simplicity, we define the agricultural supply chain as consisting of four primary functions, i.e., suppliers, farms, distributors, and consumers (Figure 1). Each of the supply chain participants is defined as follows [2]:

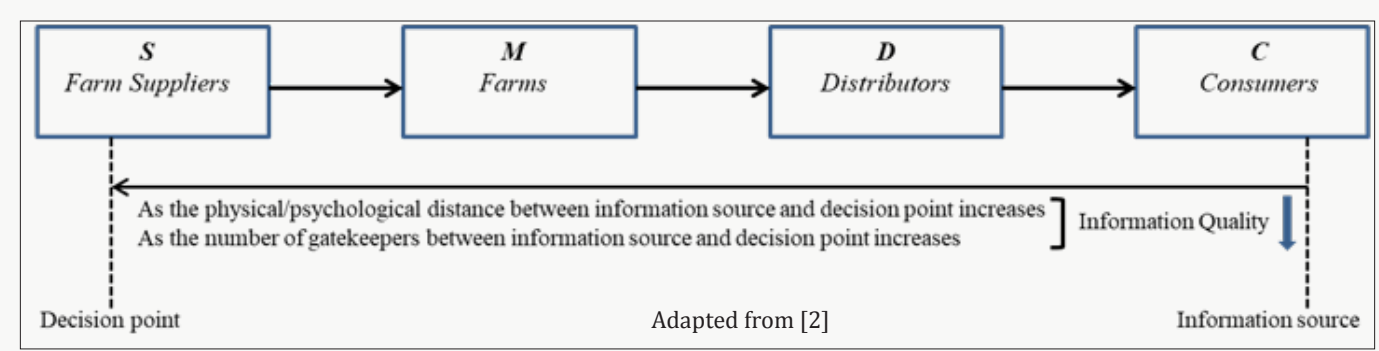

Figure 1: Agricultural Supply Chain. 
a) Suppliers are those companies or individuals, who provide raw materials or necessary supplies to the farms and farmers. These include seeds, fertilizers, pesticides, machinery, equipment, farming tools, and the like.

b) Farms are those companies or individuals, who are actually growing crops like rice, potato, corn, and beans. In order to produce those crops, farms need the farming land, water, and the supplies from the suppliers.

c) Distributors perform two functions, processing and distributing. Once the farms harvest their crops, these crops must be transported to wholesalers, who then sell the crops to retailers. Individual consumers buy their crops from the retail stores. Distributors perform this transportation function. Sometimes certain crops need to be processed, e.g., sliced, refrigerated, or canned, before being transported to wholesalers or retailers. Some of the distributors carry out this processing function.

d) Consumers are those companies or individuals, who use the crops for their businesses or their own use. Companies as consumers include restaurants or food manufacturers, who produce processed foods such as snacks, soft drinks, frozen packaged foods, and so on. Also individuals are important consumers in the agricultural supply chain.

Although the basic structure of the agricultural supply chain is similar with that of other industries, it has unique attributes that are quite unusual from other supply chains' perspectives.
Some of the conspicuous characteristics are as follows:

a) The distance, physical or even psychological, between suppliers and consumers, i.e., the length of the agricultural supply chain is in general much longer than that of other industries. It might be simply due to geographic conditions, e.g., the rural area, where most farms are located, is usually far away from the urban area, where many consumers reside. Considering social and also cultural differences between rural and urban areas, we put forth the psychological distance is also quite extensive.

b) As a supply chain's length increases, more intermediaries enter the supply chain. That is, the longer the supply chain, the more the gatekeepers involved in the transactions at various stages throughout the supply chain.

c) As a result, the agricultural industry becomes more and more fragmented, filled with small players that have myopic perspectives to optimize their own interest without considering the supply chain as a whole. But, this is not a criticism. We just want to highlight the current state of the agricultural industry. Although the individuals in the agricultural supply chain behave myopically, i.e., in a suboptimum way from the entire supply chain's perspective, it is not because these individuals are ill-intentioned, but because there might be a systemic failure in the supply chain itself. In fact, it is the quintessential proposition we have in this paper and in the next sections, we delve into explaining why it might happen.

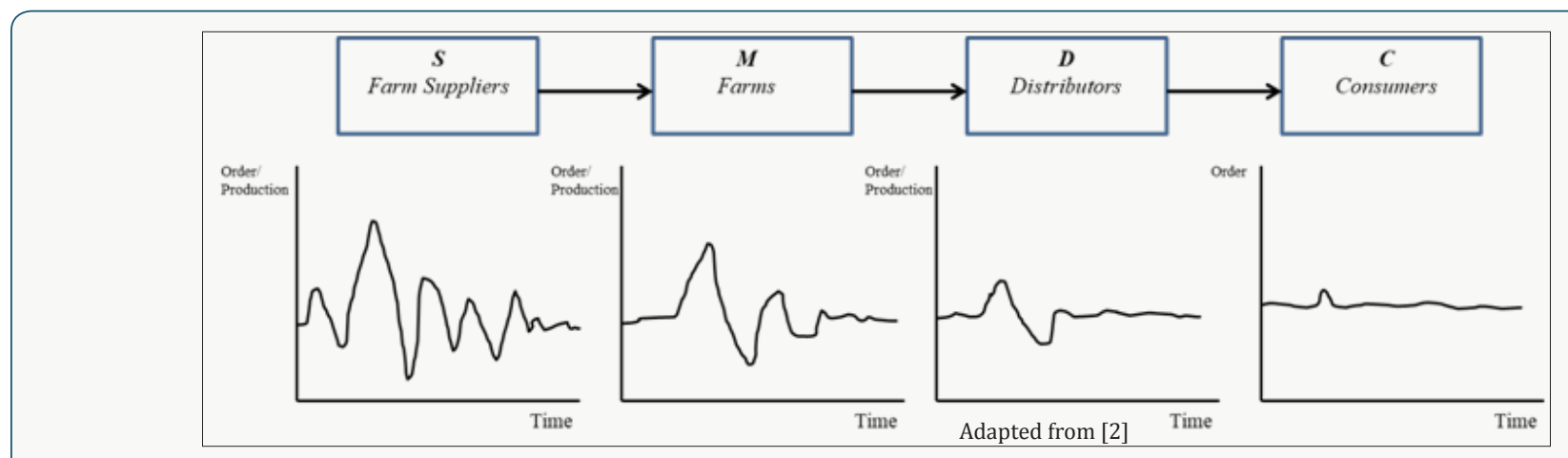

Figure 2: The Bullwhip Effect in the Agricultural Supply Chain.

\section{The Bullwhip Effect}

In order to create maximum value in an industry, its supply chain must function effectively. But it is not an easy feat to accomplish. It requires seamless coordination among the participants in the supply chain. As such, we often observe across the board breakdowns of supply chains in many different industries. One of the most conspicuous such breakdowns is the bullwhip effect, which is caused when a long and often complex supply chain makes it difficult for information and communication to flow efficiently through the chain. Let's first explain what the bullwhip effect is and how it affects the agricultural supply chain.
The bullwhip effect is the phenomenon, where the amount of order or production at an upstream function fluctuates more than that at its downstream function. As Figure 2 shows, the order or production at the distributor fluctuates more than that at the end market. The order or production at the farm (i.e., manufacturing function in a general supply chain) fluctuates more than that at the distributor, and so forth. More fluctuation means more uncertainty faced by the function in point. For instance, the uncertainty faced by the farm is greater than that faced by the distributor. Why does the bullwhip effect hurt the industry? The bullwhip effect causes the uncertainty to magnify more as the decision point moves from 
a downstream to an upstream function. There are two aspects of the uncertainty. First, there is the magnitude of fluctuation, i.e., the extent or size of the fluctuation, which becomes larger as one moves backward in the supply chain (Figure 3). The other is the time-to-stability, i.e., how long it takes to return to the stable state, which becomes longer as one moves toward an upstream function. As the uncertainty increases, other things being equal, the firm has to keep larger inventory in order to buffer against the uncertainty.

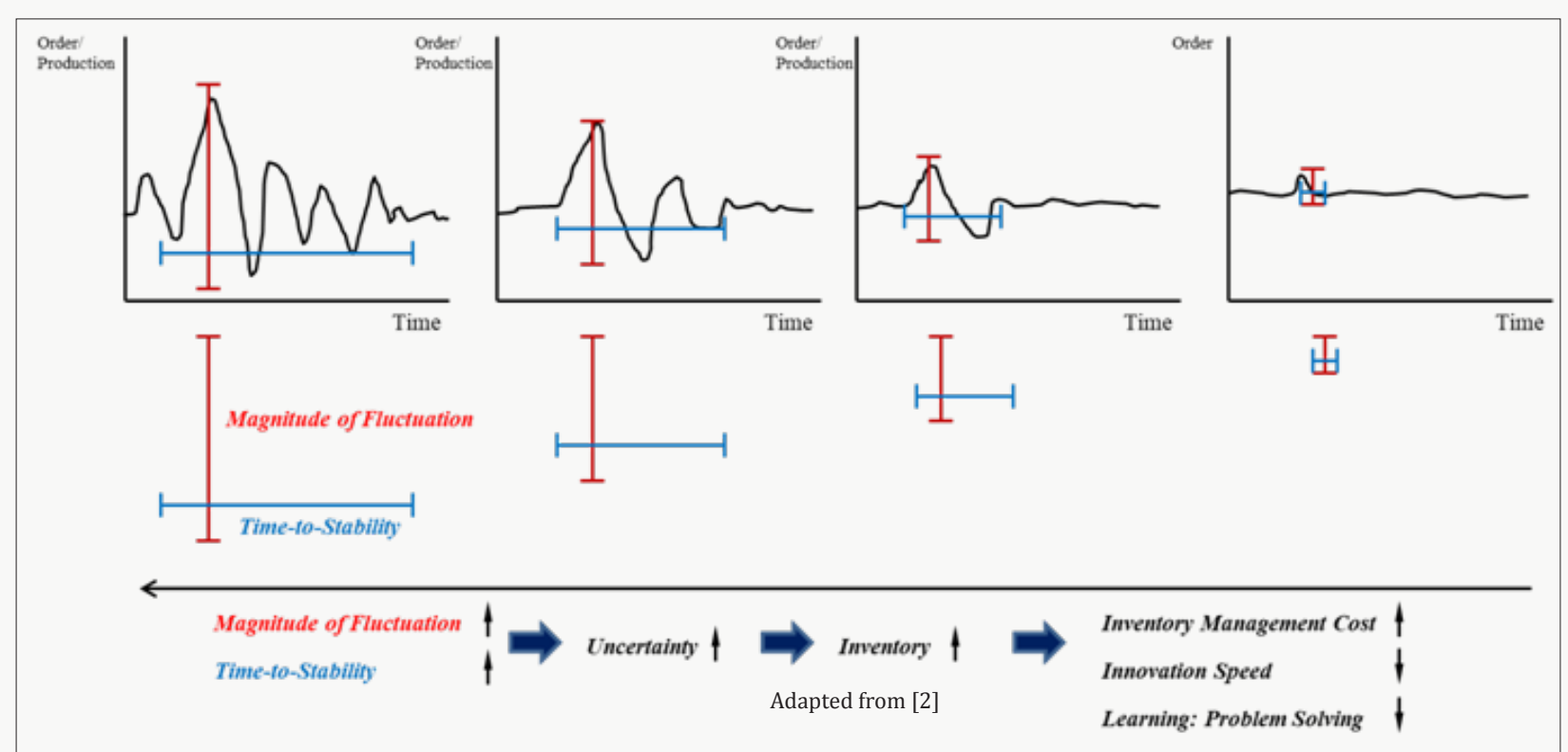

Figure 3: Consequences of the Bullwhip Effect.

A larger inventory has three negative consequences for the firm. First, more inventory means higher inventory management cost. It is the most widely mentioned consequence of keeping a large inventory. However, there are more damaging consequences than the cost itself. When it has inventory more than effectively optimal, it becomes more difficult for the firm to innovate. For instance, when the firm's warehouse is full of old, outdated inventory, it cannot introduce new products into the market, unless it is willing to write off its inventory. Finally, keeping an unnecessarily large inventory might prevent the firm from identifying and solving problems. It is due to that the inventory might cover up serious flaws in the firm so that it cannot identify managerial problems appropriately. If you cannot identify a problem, you cannot solve it. We expect these negative consequences of having an unnecessary inventory to affect the agricultural industry in the same way impacting other industries: the agricultural industry is affected by the increased inventory due to the bullwhip effect causing uncertainty throughout the supply chain in three ways. That is, due to the chronic uncertainty embedded in itself, the agricultural industry is afflicted with three deficiencies, i.e., increased inventory management cost, decreased innovation, and reduced problem solving capability.

\section{Discussion}

We have discussed why and how the bullwhip effect in the agricultural industry could cause serious inefficiencies and deficiencies in the industry. Considering the unique structure of the agricultural supply chain, we believe the negative impacts of the bullwhip effect affect the agricultural industry more severely than other industries. Is there any way to overcome these problems? To answer the question, we should think about the fundamental cause of the bullwhip effect. As Figure 1 hints, the main cause of the bullwhip effect is the poor information quality, which in turn is determined by two factors, i.e., the physical or psychological distance and the number of gatekeepers between the information source (consumer market) and the decision point (each supply chain participant). The longer the distance, the poorer the information quality. The more the gatekeepers, the poorer the information quality. As a result, in order to reduce and eventually get rid of these negative consequences of the bullwhip effect in the agricultural supply chain, we should improve the information quality. One of the most effective ways to improve the information quality is to enhance the communication for information sharing among the supply chain participants in the agricultural supply chain. Then, another relevant question is "why hasn't the communication done effectively in the agricultural supply chain?" Like human beings, firms do not communicate with each other, unless there is trust between them. This series of reasoning leads us to a logical conclusion that in order to solve the damaging problems prevalent in the agricultural industry, it is essential to dramatically enhance the trust among the partners or participants in the supply chain.

It is, however, neither easy nor straightforward to make the supply chain participants trust each other suddenly, unless a trustbased relationship has existed among them. Fortunately, there emerges a new technology that could help managers and their companies to trust other players in the supply chain, not necessarily having known each other for long. It is the blockchain technology 
[3]. In fact, there are already several cases, where the blockchain enables the supply chain to function effectively by restoring the trust among the players sharing the same value chain [4]. Although it has been regarded as a traditional industry that might not be nicely compatible with cutting-edge technological innovations, now it is the time for the agricultural industry to transform itself completely. The key to this change is technology. In particular, the agricultural industry must invest heavily in innovative technologies that help the partners and participants alike to trust each other in doing business.

\section{References}

1. Cervantes Godoy D, J Dewbre (2010) Economic Importance of Agriculture for Sustainable Development and Poverty Reduction: The Case Study of Vietnam. OECD.

2. Kim B (2018) Supply Chain Management: A Learning Perspective. Cambridge University Press, UK.

3. Iansiti M, KR Lakhani (2017) The truth about block chain. Harvard Business Review.

4. Aitken R (2017) IBM \& Walmart Launching Blockchain Food Safety Alliance, Forbes.

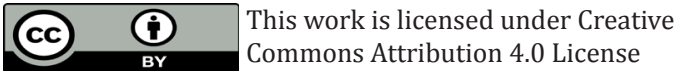

To Submit Your Article Click Here:

Submit Article

DOI: 10.32474 /CIACR.2018.02.000132

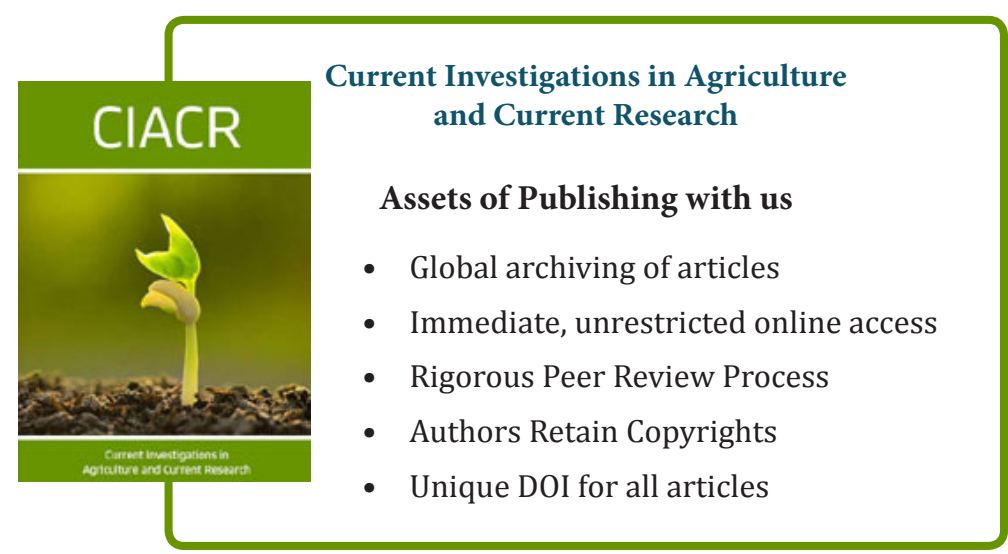

